\title{
CULTURA DE PAZ EM TEMPO DE PANDEMIA
}

\author{
CULTURE OF PEACE ON PANDEMIC AGE
}

\begin{abstract}
Alex Sander Xavier Pires ${ }^{1}$
Resumo: Paz e saúde são dois bens inatos aos seres humanos desde tempos imemoriais que receberam, nos últimos dois séculos, maior dedicação científica, principalmente no âmbito jurídico-político com repercussão internacional. Neste sentido, pretende-se analisar a formação dos sistemas de proteção da paz e da saúde, na perspectiva internacional e no âmbito normativo que lhes confere as duas maiores Organizações - Nações Unidas e Organização Mundial de Saúde -, tendo em conta o interesse em lhes conferir a força de direitos e lhes impor toda uma cultura inerente baseada no estímulo a consciência que permita aos indivíduos integrar-lhes ao dia-a-dia e transpô-las a vida social; por outro lado, pretende-se trazer elementos que estimulem a reflexão dos leitores sobre a importância e imanência da paz e da saúde para o desenvolvimento sustentável e para fruição dos direitos humanos em iguais condições para todos, o que será possível pela análise das principais Resoluções e atos constitutivos das Nações Unidas e da Organização Mundial de Saúde, especialmente àquelas que se referem a contenção da pandemia por COVID-19.
\end{abstract}

Palavras-Chave: Cultura de paz; saúde; pandemia; consciência; cooperação internacional.

\begin{abstract}
Peace and health are two goods innate to human beings since immemorial times that have received, in the last two centuries, more scientific dedication, especially in the legal-political field with international repercussions. In this sense, it is intended to analyze the formation of peace and health protection systems, in the international perspective and in the normative scope that gives them the two major Organizations - United Nations and World Health Organization -, taking into account the interest in giving them the strength of rights and imposing on them an inherent culture based on the stimulation of conscience that allows individuals to integrate them into daily life and transpose them into social life; by other side, it intends to bring elements that stimulate the reflection of the readers on the importance and immanence of peace and health for sustainable development and for the enjoyment of human rights on equal terms for all, which will be made possible by the analysis of the main Resolutions and constituent acts of the United Nations and the World Health Organization, especially those that refer to the containment of the pandemic by COVID-19.
\end{abstract}

Keywords: Culture of peace; health; pandemic; awareness; international cooperation.

\section{Introdução}

Há um século, com o término da I Grande Guerra e a assinatura do Tratado de Versalhes², determinou-se para os Membros da recém criada Liga das Nações ${ }^{3}$ o objetivo de tomada de

\footnotetext{
${ }^{1}$ Pós-doutor em Direito. Doutor em Ciências Jurídicas e Sociais. Doutor em Ciência Política. Professor universitário, atualmente lecionando nos Programas de Licenciatura, Mestrado e Doutoramento em Direito da Universidade Autónoma de Lisboa. Fundador do Projeto Pensar a Justiça. Secretário-Geral do ECII. Advogado.

${ }^{2}$ Vide Parte I do Tratado de Versalhes assinado em 28 de junho de 1919, cujo protocolo foi assinado pela Alemanha em 19 de janeiro de 1920. Disponível em: <<https://www.loc.gov/law/help/us-treaties/bevans/m-ust0000020043.pdf $\gg$, último acesso em 09 de julho de 2020.

${ }^{3}$ A depender da acepção e do interesse da tradução, "Sociedade das Nações".
} 
medidas de prevenção e controle de doenças de interesse internacional (art. 23, f), que, em sendo objeto de deliberação na Segunda Conferência do Conselho (fevereiro de 1920), deu origem a Conferência Internacional dos Peritos em Saúde com a intenção de alinhavar a estrutura para criação de uma Organização Internacional de Saúde, em abril de 1920.

No âmbito da Conferência Internacional dos Peritos em Saúde, para além dos debates sobre os critérios de estruturação para criação da Organização Internacional de Saúde, foi necessário discutir o grave problema de epidemia de tifo, febre e cólera que se espalhara da Rússia para os países do leste europeu, cujo resultado foi a recomendação para instauração da temporária Comissão Epidêmica (League of Nations, 1931,p. 3).

Com a criação da Comissão Epidêmica várias medidas coordenadas foram tomadas, com a criação, inclusive, de cordões sanitários, programas de vacinação coletiva, tratamentos médicohospitalares com protocolos comuns, entre outros. A mobilidade dos refugiados e os novos movimentos militares (p.ex. a guerra russo-polaca e a intentona turca na Ásia Menor) desafiaram a atenta, preventiva e interventiva participação da Comissão que conseguiu importantes resultados em 1922.

Durante a atuação emergencial da Comissão Epidêmica foi instaurado o Comitê de Saúde que, atuando conjuntamente com o Gabinete Internacional de Higiene Pública, conseguiu definir o regime da Organização de Saúde aprovado no $4^{\circ}$ Período de Sessões do Conselho (1923). De mais marcante registra-se que tanto a Comissão como a Organização não são organismos políticos (League of Nations, 1931, p. 5).

Na prática, para além da função de atuar na prevenção e intervenção de doenças no âmbito internacional, a Organização de Saúde também atuou em conjunto com a Organização Internacional do Trabalho - outra organização internacional nascida com o Tratado de Versalhes -, para mapeamento, controle e erradicação de doenças laborais, conjuntamente com questões de seguridade social; e outras autoridades de saúde dos mais diversos Estados (League of Nations, 1931, p. 29).

O Tratado de Versalhes e a Liga das Nações não conseguiram conter as tensões internacionais que culminaram na II Grande Guerra, cujos catastróficos resultados de perdas humanas, patrimoniais (materiais e imateriais), e psicológicas desafiaram a reconstrução do sistema instaurado. Assim, a Liga das Nações deu origem à Organização das Nações Unidas (ONU), e a Organização da Saúde transformou-se, de fato e de direito, na World Health Organization (WHO) - Organização Mundial de Saúde (OMS).

A OMS e a ONU estão ligadas umbilicalmente, seja pela intenção de vinculação das questões sanitárias como elemento inerente a concepção dos parâmetros sobre os quais se concebeu a ONU a partir de 1941, seja pelas normas estatutárias, de ambas, que preveem a colaboração e cooperação recíprocas pelo art. 57 da Carta das Nações Unidas e, também, pelo Preâmbulo da Constituição da OMS ao impor aos Estados Partes o reconhecimento dos Princípios 
estruturantes das Nações Unidas em aderência temática às suas funções.

Ademais, como acontecido em outras épocas, vive-se a pandemia de COVID-19 conforme declarado pela OMS em 11 de março 20204. Tal constatação permite inúmeras abordagens, inclusive a de natureza jurídica, e, mais, a restrição em nível de Resoluções, conjuntas e separadas, entre ONU e OMS acerca de um dos propósitos declarado por ambas: a persecução da paz internacional perpétua. Assim, a presente reflexão pretende ponderar a relação da cultura de paz, em discurso positivo e propositivo, no âmbito das duas entidades, diante do atual desafio pandêmico.

\section{Formação das Nações Unidas: uma organização dedicada a paz e a segurança internacionais}

A criação da Liga das Nações ao término da Primeira Guerra Mundial não foi suficiente para instaurar o estado de paz assentado na cessação permanente das hostilidades entre as nações, o que se percebe com o início da Segunda Guerra Mundial.

Neste âmbito, em 1941, pelas resoluções constantes do Acordo de St. James ${ }^{5}$, percebe-se o recrudescer da ideia de associação dos Estados soberanos, agora sob a concepção de povos livres, para, reunidos e convergidos ao firme propósito de perseguir a paz duradoura mediante a cooperação voluntária entre si, combaterem a coação pela violência incluindo a ameaça de agressão assentando o estado de segurança, econômica e social, livre de ameaças, que, desde a Carta do Atlântico ${ }^{6}$ deveria incidir sobre a redução da força bélica mediante políticas internacionais de desarmamento concebidas num sistema geral de segurança.

Com inspiração nos princípios da Carta do Atlântico ${ }^{7}$, em 1942, publicou-se a Declaração pelas Nações Unidas em que os vinte e seis Estados signatários originários ${ }^{8}$ comprometeram-se em somar esforços, militares e econômicos, em cooperação para por fim a guerra em vias de defender a vida, a liberdade, a independência e a liberdade religiosa, bem como preservar os direitos humanos e a justiça, para si e para os demais territórios.

A Declaração pelas Nações Unidas levou à Declaração de Moscou sobre a segurança geral ${ }^{9}$

\footnotetext{
${ }^{4}$ Fonte: $<<$ https://www.who.int/news-room/detail/27-04-2020-who-timeline---covid-19>>, último acesso em 30/07/2020.

${ }^{5}$ Disponível em: $<<$ http://avalon.law.yale.edu/imt/imtjames.asp >>, último acesso em 30/05/2019.

${ }^{6}$ Disponível em: $<<$ http://avalon.law.yale.edu/wwii/atlantic.asp >>, último acesso em 30/05/2019.

${ }^{7}$ Disponível em: <<https://www.unmultimedia.org/searchers/yearbook/page.jsp?volume=194647\&page=36\&searchType $=$ advanced $>>$, último acesso em 30/05/2019.

${ }^{8}$ Até 1945 aderiram mais vinte e um Estados.

${ }^{9}$ Disponível em: <<https://www.unmultimedia.org/searchers/yearbook/page.jsp?volume=1946-47\&page=38>>, último acesso em 30/05/2019.
} 
reconhecendo a necessidade de, rápida e ordenadamente, acabar com a guerra e instaurar a paz com o mínimo de dispêndio possível de recursos humanos e econômicos, e, desde então, estabelecer e manter a paz e a segurança internacionais.

Para tanto, dever-se-ia estabelecer, o mais rapidamente possível, uma organização internacional geral aberta à participação de todos os Estados, grandes e pequenos, para a manutenção da paz e da segurança internacionais, com base no princípio da igualdade soberana de todos os Estados amantes da paz (art. $4^{\circ}$ ), que, desde a cessação das hostilidades da Segunda Guerra Mundial, deveriam atuar em cooperação mediante consultas, prévias e recíprocas, especialmente para restabelecimento do direito e da ordem ( $\left.\operatorname{art} .5^{\circ}\right)$, com restrição ao uso da força militar apenas para manutenção dos propósitos da segurança geral, mediante consulta aos demais Estados e em operação conjunta com a comunidade de nações (art. $6^{\circ}$ ), tendo em vista a aproximação de todos para regulamentação do uso de armamento $\left(\operatorname{art.} 7^{\circ}\right)$.

A Declaração de Moscou sobre a segurança geral assentou as bases para as Conversas de Dumbarton Oaks ${ }^{10}$, ocorridas em 1944, que convergiu a apresentação da Proposta para Estabelecimento da Organização Internacional Geral a ser denominada de Nações Unidas e regulamentada por sua Carta própria baseada nos firmes propósitos da persecução da paz e da segurança internacionais possíveis pela instauração de mecanismos que afastassem as ameaças de agressão e outros expedientes contra a paz mediante a concepção de meios pacíficos e ajustados para solução das disputas entre os Estados, bem como o desenvolvimento de relações amigáveis entre as nações que favorecesse o fortalecimento de uma paz universal.

As Conversas de Dumbarton Oaks foram sucedidas pelo Acordo de Yalta ${ }^{11}$ que, para além de resolver a questão do procedimento de votação e confirmação da decisão de estabelecimento breve da organização internacional geral para instauração e manutenção da paz e da segurança internacionais, reafirmou a necessidade de colaboração estreita e contínua de todos os povos amantes da paz, tanto para impedir a agressão como para eliminar as causas políticas, econômicas e sociais da guerra.

\section{Carta das Nações Unidas: fundamentos, propósitos e princípios inspiradores do sistema de paz}

Em 26 de junho de 1945, como conclusão da Conferência das Nações Unidas sobre Organização Internacional (Conferência de San Francisco), foi assinada a Charter of the United

\footnotetext{
${ }^{10}$ Disponível em: <<https://www.unmultimedia.org/searchers/yearbook/page.jsp?volume=194647\&page $=39 \&$ search Type $=$ advanced $>>$, último acesso em 30/05/2019.

"Disponível em: <<https://www.unmultimedia.org/searchers/yearbook/page.jsp?volume=194647\&page $=44 \&$ searchType $=$ advanced $>>$, último acesso em 30/05/2019.
} 
Nations (Carta das Nações Unidas ${ }^{12}$ ), composta por cento e onze artigos distribuídos em dezenove capítulos, cuja vigência se deu a partir de 24 de outubro de 1945; a que se integra o Estatuto da Corte Internacional de Justiça com setenta artigos sistematizados em cinco capítulos.

O Preâmbulo da Carta inicia por reconhecer o paradigma humanitário e associativo quando trás ao debate a reunião de povos - não de Estados em relação fenomenológica de poder - com o fim uníssono de manutenção da paz e da segurança internacionais que obstassem novas guerras de proporções mundiais, num ambiente de confiança nos direitos fundamentais, na igualdade ampla e irrestrita entre todos, na dignidade e no valor, sempre centrados no ser humano, independentemente da nação em que estivesse.

Por esta orientação, a Carta das Nações Unidas determina como finalidade: a) preservação das gerações futuras do flagelo da guerra; b) reafirmação dos direitos fundamentais, da dignidade do ser humano, e da igualdade de direitos ${ }^{13}$; c) estabelecimento de condições para a concretização da justiça, e de bases para o respeito às obrigações decorrentes de tratados e de outras fontes de direito internacional; e, d) promoção, inspirada pelo princípio da liberdade mais ampla, para o progresso social, e para melhores condições de vida.

Outrossim, são mecanismos antevistos na Carta para consecução destas finalidades: a) prática da tolerância; b) convívio em paz por inspiração das práticas de boa vizinhança; c) busca da manutenção da paz; d) persecução da segurança internacional; e) reconhecimento, em nível de garantia, de uso consciente e limitado das forças armadas; e, f) emprego de mecanismos internacionais para promoção do progresso econômico e social de todos os povos.

No âmbito dos propósitos, determina a Carta das Nações Unidas: a) a manutenção da paz e da segurança, internacionais ${ }^{14}$ (art. 1, 1, primeira parte); b) o desenvolvimento das relações $\operatorname{amistosas}^{15}$ entre as nações em vias de fortalecer a paz universal (art. 1, 2, primeira parte); c) a consecução da cooperação internacional para resolução dos problemas de caráter econômico, social, cultural, ou humanitário (art. 1, 3, primeira parte); d) a consecução da cooperação internacional para promoção e estímulo do respeito aos direitos humanos para todos, sem distinção de raça, sexo, língua ou religião (art. 1,3, segunda parte); e) a consecução da cooperação

\footnotetext{
${ }^{12}$ Disponível em: <<http://dag.un.org/bitstream/handle/11176/387353/PORTUGUESE1976.pdf? sequence=1\&isAllowed=y $>>$, último acesso em 30/05/2019.

${ }^{13}$ Igualdade de direitos, tanto dos homens entre si (leia-se, também, entre homens e mulheres), como das nações, grandes e pequenas.

${ }^{14}$ Para manutenção da paz e da segurança internacionais deve-se "tomar, coletivamente, medidas efetivas para evitar ameaças à paz e reprimir os atos de agressão ou outra qualquer ruptura da paz e chegar, por meios pacíficos e de conformidade com os princípios da justiça e do direito internacional, a um ajuste ou solução das controvérsias ou situações que possam levar a uma perturbação da paz" (art. 1, 1, in fine)

${ }^{15}$ Para o desenvolvimento das relações amistosas entre as nações em vias de fortalecer a paz universal, consignou-se o "respeito ao princípio da igualdade de direitos e de autodeterminação dos povos", além de outras medidas apropriadas (art. 1, 1, infine).
} 
internacional para promoção e estímulo do respeito às liberdades fundamentais para todos, sem distinção de raça, sexo, língua ou religião (art. 1, 3, terceira parte); e, f) a assunção de "centro destinado a harmonizar a ação das nações para a consecução" dos objetivos comuns (art. 1,4).

Ademais, as Nações Unidas, além de coactar os Estados não Membros a observância dos preceitos para manutenção da paz e da segurança internacionais (art. 2, 6) e garantir a não intervenção ou a obrigação de submissão em assuntos concernentes aos interesses essencialmente da jurisdição dos Membros (art. 2, 7), prevê como princípios, sem prejuízo de outros: a) igualdade de todos os seus membros (art. 2, 1); b) boa-fé no cumprimento das obrigações assumidas no âmbito da Carta (art. 2, 2); c) resolução pacífica das controvérsias internacionais (art. 2,3); d) vedação a prática da ameaça, nas relações internacionais, entre Estados (art. 2, 4, primeira parte); e) vedação do uso da força "contra a integridade territorial ou a independência política de qualquer Estado" (art. 2, 4, segunda parte); f) vedação de práticas incompatíveis com os propósitos das Nações Unidas (art. 2, 4, in fine); g) prestação de assistência em qualquer ação tomada em função da Carta (art. 2, 5, primeira parte); e, h) abstenção de prestar auxílio a qualquer Estado que esteja sobre interferência, preventiva ou coercitiva, das Nações Unidas (art. 2, 5, in fine).

\section{Sistema de paz e a Assembleia Geral das Nações Unidas ${ }^{16}$ em quatro passos}

Longe de encerrar o sistema de paz, a Carta das Nações Unidas deflagrou a árdua tarefa de formação da consciência individual possibilitada pelo amadurecimento moral baseado na constante e perpétua manutenção da paz e da segurança internacionais num ambiente de cooperação, diálogo e respeito, por seres humanos, povos, nações e Estados, cuja hercúlea missão em nível coletivo coube a Assembleia Geral.

Nesta seara, propõe-se a análise, em quatro passos, do sistema de paz das Nações Unidas concebido: a um, pelo assentamento das bases para a concepção do sistema com restrição temporal nos cinco primeiros períodos de sessões, mormente entre o terceiro e o quinto (A/RES/3/190; A/RES/3/217; A/RES/4/290;A/RES/5/377; A/RES/5/380; A/RES/5/381; e, A/RES/5/494); a dois, pela instauração da cultura de paz (A/RES/53/243; A/RES/33/73; e, $\mathrm{A} / \mathrm{RES} / 39 / 11)$; a três, pela declaração sobre o direito à paz (A/RES/71/189); e, a quatro, pela promoção da paz como requisito vital para o pleno desfrute dos direitos humanos para todos (A/RES/33/170).

\footnotetext{
${ }^{16}$ AAssembleia Geral é um dos principais órgãos das Nações Unidas (Carta, art. 7) formada pela representação, com no máximo cinco representantes (Carta, art. 9, 2), de todos os membros (Carta, art. 9, 1), cuja regulamentação está prevista entre os artigos 9 e 22.
} 


\section{0 anos desde o início da concepção do sistema}

A quebra do paradigma anterior impôs um período de adaptação ao novo sistema de paz introduzido pela Carta das Nações Unidas que alçara a paz e segurança internacionais ao nível de Propósito para toda a Humanidade, em nível de povos em coletividade de seres humanos e em igualdade, mas também por nações pequenas e grandes, e por representação política dos Estados (veja-se: ser humano, povo, nação e Estado). Assim, os cinco primeiros períodos de sessões da Assembleia Geral serviram a formação [rectius, adequação] das bases dos sistema de paz.

Importante passo foi dado no $3^{\circ}$ Período de Sessões da Assembleia Geral das Nações Unidas ocorrido entre 1948 e 1949, tanto pela A/RES/3/190 ${ }^{17}$ (Apelo às grandes potências para renovação dos esforços para compor suas diferenças e estabelecerem a paz definitiva) como pela $\mathrm{A} / \mathrm{RES} / 3 / 217^{18}$ (Carta Internacional dos Direitos do Homem, que, introduziu, em cinco partes a Declaração Universal dos Direitos do Homem [A/RES/3/217(A)], o Direito de Petição [A/RES/3/217(B)], o Destino das Minorias [A/RES/3/217(C)], a Publicidade a ser dada a Declaração Universal dos Direitos Humanos [A/RES/3/217(D)], e a Preparação de um Projeto de Pacto Relativo aos Direitos Humanos e das Medidas de Implementação [A/RES/3/217(E)].

A A/RES/3/190, dentre outras disposições, preocupou-se em: a) criar a consciência para acabar definitivamente com as hostilidades da Segunda Guerra Mundial mediante a conclusão e início de cumprimento dos tratados de paz; b) perseguir os firmes propósitos de instauração da paz e da manutenção da segurança internacionais, instando as potências vencedoras a aplicarem, na prática, a deliberação aprovada em teoria; c) convocar os membros a resolução das diferenças e tensões no âmbito das Nações Unidas por ter como função principal, inspirada pela cooperação e pela ajuda mútua entre os povos e nações, a composição dos elementos que possam atentar contra a paz e a segurança; e, d) reafirmar, principalmente, a Declaração de Yalta e a Carta do Atlântico.

A Declaração Universal dos Direitos do Homem, no âmbito da Carta Internacional dos Direitos Humanos (A/RES/3/217) e restrita a paz, pende a reconhecer a dignidade humana e os direitos iguais e inalienáveis como fundamento da paz no mundo (Preâmbulo), além de aproximar à educação qualificada em nível de instrução tendente ${ }^{19}$ a contribuir com a compreensão, a tolerância e a amizade entre as nações e seres humanos ${ }^{20}$ (art. XXVI, 2).

O $4^{\circ}$ Período de Sessões da Assembleia Geral das Nações Unidas ocorrido entre 1949 e

\footnotetext{
${ }^{17}$ Disponível em: <<https://www.un.org/en/ga/search/view_doc.asp?symbol=A/RES/190(III)>>, último acesso em 30/05/2019.

${ }^{18}$ Disponível em: $<<$ https://www.un.org/en/ga/search/view_doc.asp?symbol=A/RES/217(III)>>, último acesso em 30/05/2019.

19 "A instrução será orientada no sentido do pleno desenvolvimento da personalidade humana e do fortalecimento do respeito pelos direitos humanos e pelas liberdades fundamentais. (...)" (art. XXVI, 2, primeira parte).

${ }^{20}$ Há, aqui, a ressalva que "a compreensão, a tolerância e a amizade" são tratadas no sentido de adoção "entre todas as nações e grupos raciais ou religiosos" (art. XXVI, 2, segunda parte).
} 
1950 foi marcado pela A/RES/4/290 (Fundamentos da paz) que contém, dentre os treze dispositivos, a declaração do art. $1^{\circ}$ que $e^{21}$ se divide em quatro pontos: a um, determina a Carta das Nações Unidas como o Pacto de Paz mais solene da História; a dois, esclarece que a Carta das Nações Unidas estabelece os princípios básicos para a paz duradoura; a três, alerta que a desconsideração destes princípios é a principal responsável pela continuação da tensão internacional; e, a quatro, orienta que é urgentemente imprescindível que os Membros adotem os princípios, e sigam-nos, em respeito ao espírito de cooperação que norteia as relações no âmbito das Nações Unidas.

O $5^{\circ}$ Período de Sessões da Assembleia Geral das Nações Unidas ocorrido entre 1950 e 1951 caracterizou-se pela aprovação de quatro resoluções: A/RES/5/377 (Unindo[-nos] pela paz);A/RES/5/380 (Paz por ações); A/RES/5/381 (Condenação da propagảnda contra a paz); e, A/RES/5/494 (D'esenvolvimento do Programa ${ }^{24}$ de 20 -anos para alcançar a paz através das Nações Unidas ${ }^{25}$.

A A/RES/5/377 (Unindo[-nos] pela paz) distribui o tema em cinco partes em vias de assentar os dois primeiros propósitos da Carta das Nações Unidas : a) ao considerar a difícil formação da unanimidade no Conselho de Segurança, propôs-še a Emenda a Regra de Procedimento da Assembleia Geral, acompanhada de duas "recomendações ao Conselho de Segurança"; b) propõe a criação da Comissão de Observação da Paz; c) convida cada Membro a analisar e determinar a possível disponibilização de recursos militares a serem postos a serviço das Nações Unidas; d) promove a criação do Comitê de Medidas Coletivas; e, e) renova o interesse no assentamento da consciência que a segurança e a paz definitiva dependem do cumprimento, por todos (principalmente os Membros do Conselho de Segurança), dos Princípios e Finalidades da Carta da Nações Unidas.

AA/RES/5/380 (Paz por ações), em sentido amplo, conclamou a comunidade internacional (Estados e Povos) a partir para ação na persecução da paz e da segurança, mediante o controle de alguns atos/fenômenos (item 2) e da consciência de não intervenção de um Estado em outro,

${ }^{21}$ Disponível em: $<<$ http://www.un.org/en/ga/search/view_doc.asp?symbol=A/RES/290(IV) >>, último acesso em 11/03/2019.

${ }^{22}$ Disponível em: <<http://www.un.org/en/ga/search/view_doc.asp?symbol=A/RES/377(V)>>, último acesso em 12/03/2019.

${ }^{23}$ Disponível em: $<<$ http://www.un.org/en/ga/search/view_doc.asp?symbol=A/RES/380(V) $>>$, último acesso em 12/03/2019.

${ }^{24}$ Disponível em: <<http://www.un.org/en/ga/search/view_doc.asp?symbol=A/RES/381(V)>>, último acesso em $12 / 03 / 2019$

${ }^{25}$ Disponível em: <<http://www.un.org/en/ga/search/view_doc.asp?symbol=A/RES/494(V)>>, último acesso em 12/03/2019.

${ }^{26}$ Lembra-se: manter a paz e a segurança internacionais baseadas nos princípios de justiça e de direito internacional; e, desenvolver as relações amistosas entre as nações com observância aos princípios dos direitos iguais e da autodeterminação dos povos. 
tampouco de abusos no uso do poder público em seu próprio território (item 1).

A A/RES/5/381 (Condenação da propaganda contra a paz) reafirmou as Resoluções $\mathrm{A} / \mathrm{RES} / 2 / 110$ (Medidas a serem tomadas contra a propaganda e os incitadores de uma nova guerra) e A/RES/4/290 (Fundamentos da paz), ao definir os atos vedados e o "sentido" do que vem a ser "propaganda čntra a paz".

AA/RES/5/494 (Desenvolvimento do Programa de 20-anos para alcançar a paz através das Nações Unidas) conclama a elaboração do "Memorandum" pela paz de iniciativa do Secretário Geral.

\section{0 anos da Declaração sobre a Cultura de Paz}

Por ocasião do $53^{\circ}$ Período de Sessões, em 1998/1999, aprovou-se a A/RES/53/243 tanto dedicada, na primeira parte, à Declaração sobre a Cultura de Paz como, na segunda, ao Prơgrama de Ação sobre a Cultura de Paz, que partem da reafirmação da paz e da segurança internacionais como propósito e princípio das Nações Unidas, em nível de Carta, de Declaração Universal dos Direitos do Homem, e dos demais instrumentos que constituíam - e constituem - o sistema de proteção e instauração da paz, como, por exemplo, a Declaração sobre a Preparação das Sociedades para Viver em Paz (A/RES/33/73) , e a Declaração sobre o Direito dos Povos à Paz (A/RES/39/11) .

$\mathrm{Na}$ Declar̉ação sobre a preparação das sociedades para viver em paz (A/RES/33/73), foram consignados os seguintes princípios: a) todos, nações e seres humanos, têm o direito imanente de viver em paz, independentemente das particularidades (art. 1); b) o planejamento, a preparação ou o início de uma guerra de agressão constituem crimes contra a paz e são proibidos pelo direito internacional (art. 2 c/c art. 5, 2 d’ả Resolução no 29/3314); c) os Estados, de acordo com os propósitos e princípios das Nações Unidas, devem se abster de fazer propaganda a favor das guerras de agressão (art. 3); d) todo Estado, inspirado pela amizade, pelas práticas de boa vizinhança e independentemente de sua condição sócio-econômica particular, deve promover a

\footnotetext{
${ }^{27}$ Disponível em: $<<$ http://www.un.org/en/ga/search/view_doc.asp?symbol=A/RES/110(II)>>, último acesso em $12 / 03 / 2019$.

${ }^{28}$ Disponível em: <<http://www.un.org/en/ga/search/view_doc.asp?symbol=A/RES/290(IV)>>, último acesso em 11/03/2019.

${ }^{29}$ Disponível em: <<https://www.un.org/en/ga/search/view_doc.asp?symbol=A/RES/53/243>>, último acesso em 30/05/2019.

${ }^{30}$ Disponível em: $<<$ https://www.un.org/en/ga/search/view_doc.asp?symbol=A/RES/33/73>>, último acesso em 30/05/2019

31 Disponível em: <<https://www.un.org/en/ga/search/view_doc.asp?symbol=A/RES/39/11 >>, último acesso em $30 / 05 / 2019$.

${ }^{32}$ Dentre outros dispositivos, a agressão que denota a guerra tem previsão no art. 3 da Resolução no $29 / 3314$.
} 
cooperação, benéfica e equitativa, com outros Estados, nos planos político, econômico, social e cultural (art. 4); e) todo Estado deve respeitar o direito de todos os povos a autodeterminação, a independência, a igualdade, a soberania, a integridade territorial dos Estados e a inviolabilidade de suas fronteiras (art. 5); f) há que se eliminar a ameaça da corrida armamentista, ao mesmo tempo que se deve promover esforços para um desarmamento geral e completo, sob controle internacional (art. 6); g) todo Estado deve desestimular as manifestações e práticas de colonialismo, racismo, discriminação racial e apartheid (art. 7); e, h) todo Estado deve desestimular, igualmente, a promoção do ódio e do preconceito contra outros povos (art. 8).

A Declaração sobre o Direito dos Povos à Paz (A/RES/39/11) registrou o discurso direto sobre a necessidade de se prevenir uma catástrofe nuclear mundial mediante o estabelecimento de uma paz duradoura em todo o planeta, em vias de se preservar a existência e a civilização humana. Assim, este instrumento determina que todos os povos têm o direito sagrado à paz (art. 1), de igual modo que impõe a obrigação fundamental de todos os Estados garantirem este direito sagrado (art. 2), mediante a adoção de políticas públicas de eliminação da ameaça da guerra (especialmente a nuclear), da renúncia do uso da força nas relações internacionais, e da resolução pacífica das controvérsias de acordo com a Carta (art.3).

Ademais, deu seguimento a A/RES/52/15 que proclamou o ano de 2000 como "ano internacional para a cultura de paz", e, também, a $\mathrm{A}^{3} / \mathrm{RES} / 53 / 25$ que declarou o período de 2001 2010 como a "década para a cultura de paz e não-violência para ảs crianças do mundo".

Especificamente no âmbito da Declaração sobre uma Cultura de Paz acolhida na A/RES/53/243, de 06 de outubro de 1999, inspirada e possibilitada pelo término da guerra fria, reconhecem-se três assertivas: a primeira, as guerras nascem na mente dos seres humanos, de forma que é ali que se deve fortalecer a paz (premissa dantes declarada na Constituição da Organização das Nações Unidas para a Educação, a Ciência e a Cultura); a segunda, a percepção que a paz, mais do que a simples ausência de conflito, requer um processo positivo, dinâmico e participativo, de promoção do diálogo em vias de se buscar a solução negociada em um espírito de entendimento e cooperação de todos os atores; e, a terceira, a concreta necessidade de se perquirir a eliminação de todas as formas de discriminação e intolerância.

A justificar as assertivas, a Declaração assume que o sucesso na implementação da cultura de paz somente é possível pela disseminação de valores, atitudes, comportamentos, e estilos de vida dedicados exclusivamente ao fomento da paz entre as pessoas, os grupos e as nações (art. 2); sendo a educação, em todos os níveis e voltada a difusão dos direitos humanos, o meio

\footnotetext{
${ }^{33}$ Disponível em: $<<$ https://www.un.org/en/ga/search/view_doc.asp?symbol=A/RES/52/15>>, último acesso em $30 / 05 / 2019$

${ }^{34}$ Disponível em: <<https://www.un.org/en/ga/search/view_doc.asp?symbol=A/RES/53/25>>, último acesso em 30/05/2019.
} 
fundamental para sua edificação (art. 4), enquanto todos devem se comprometer com o seu fortalecimento, ou seja, os governos têm a função primordial de promovê-la (art. 5), a sociedade civil tem o compromisso com o seu desenvolvimento pleno (art. 6), a grande mídia deve contribuir com a difusão da informação qualificada e educativa (art. 7), as Nações Unidas devem seguir com sua missão de desempenhar a função crítica conducente ao fortalecimento do movimento (art. 9), e os pais, professores, políticos, jornalistas, órgãos e grupos religiosos, intelectuais, todos os que realizem atividades científicas, filosóficas, criativas e artísticas, sanitaristas, humanitaristas, diretores de organizações governamentais e não governamentais, a quem assiste a função chave de promover a cultura de paz (art. 8).

Outrossim, a cultura de paz, enquanto conjunto de valores, atitudes, tradições, comportamentos e estilos de vida se baseia: a) no respeito a vida, no fim da violência, na promoção da prática de não violência por meio da educação, do diálogo e da cooperação (art. 1, a); b) no respeito aos princípios da soberania, da integridade territorial, da independência política dos Estados, e da não interferência nos assuntos eminentemente de jurisdição interna dos Estados (art. $1, \mathrm{~b})$; c) no respeito irrestrito e na difusão dos direitos humanos e das liberdades fundamentais (art. 1, c); d) no compromisso com a solução pacífica de conflitos (art. 1, d); e) no esforço para satisfação das necessidades de desenvolvimento e proteção do meio-ambiente (art. 1, e); f) no respeito e promoção do direito ao desenvolvimento (art. 1, f); g) no respeito e difusão da igualdade de direitos e oportunidades, especialmente entre mulheres e homens (art. 1, g); h) no respeito e promoção do direito de todas as pessoas as liberdades de expressão, de opinião e de informação (art. 1, h); e, i) na adesão aos princípios de liberdade, justiça, democracia, tolerância, solidariedade, cooperação, pluralismo, diversidade cultural, diálogo e entendimento em todos os níveis da sociedade e entre as nações (art. 1,i).

\section{Contemporaneidade: Declaração sobre o Direito à Paz}

Firmadas as bases ideológicas com assento, dentre outros ${ }^{35}$, na Carta das Nações Unidas, na Declaração Universal dos Direitos Humanos, no Pacto Internacional de Direitos Civis e Políticos, no Pacto Internacional dos Direitos Econômicos, Sociais e Culturais, na Declaração sobre o Direito ao Desenvolvimento, na Declaração e no Programa de Ação de Viena, na Preparação das Sociedades para Viver em Paz, na Declaração sobre o Direito dos Povos à Paz, e na Declaração e Programa de Ação sobre uma Cultura de Paz; aprovou-se a Declaração sobre o Direito à Paz

\footnotetext{
${ }^{35}$ Por exemplo, a Declaração do Milênio (A/RES/55/2), a Agenda 2030 para o Desenvolvimento Sustentável (A/RES/70/1), o Documento Final da Cúpula Mundial 2005 (A/RES/60/1), A Declaração sobre os princípios de Direito Internacional, especialmente os referentes as relações de amizade e de cooperação entre os Estados (A/RES/25/2625), a Definição de Agressão (A/RES/29/3314), e a Declaração sobre a Concessão da Independência aos Países e Povos Coloniais (A/RES/25/1514).
} 
(A/RES/71/189 $\left.9^{36}\right)$ concebida em sintéticos cinco artigos.

Sem prejuízo da concepção de todos - nações e seres humanos - terem o direito imanente de viver em paz, independentemente das particularidades (A/RES/33/73, art. 1), e que tal direito é sagrado (A/RES/39/11, art. 1), estendeu-se a interpretação para que acolhesse, também, o desfruto da paz, no sentido de promoção e proteção de tođ̛os os direitos humanos e o alcance do desenvolvimento pleno, para todos (A/RES/71/189, art. 1 ); o que seria possível com o respeito, a aplicação e a promoção da igualdade e da não discriminação, da justiça e do estado de direito, e da garantia contra o medo e a miséria, sem prejuízo de outros direitos avocados no âmbito da Carta das Nações Unidas, da Declaração Universal dos Direitos ${ }^{38}$ Humanos, e de instrumentos internacionais e regionais sobre a temática ( $\mathrm{A}^{39} \mathrm{RES} / 71 / 189$, art. 5 ), alçados a condição de deveres oponíveis aos Estados (A/RES/71/189, art. 2 ), extensível as Nações Unidas e as agências/órgãos especializados nos limites de suas competências, responsabilidades e atuações (A/RES/71/189, art. 3).

Para cumprimento do dever de garantir o desfruto da paz no ambiente dos direitos humanos e na persecução do pleno desenvolvimento, os Estados, as Nações Unidas e as agências/órgãos especializados devem adotar medidas sustentáveis e adequadas a consecução do múnus; de igual forma que se conclama ao apoio e à assistência das organizações internacionais, regionais, nacionais e locais, bem como à sociedade civil (A/RES/ 71/189, art. 3 ). Em todos os casos a educação adequada e inspirada nos valores da tolerância, do diálogo, da cooperação e da

\footnotetext{
${ }^{36}$ Disponível em: <<https://www.un.org/en/ga/search/view_doc.asp?symbol=A/RES/71/189>>, último acesso em 30/05/2019.

37 "Artigo 1. Toda pessoa tem o direito de desfrutar da paz de modo que todos os direitos humanos sejam promovidos e protegidos e o desenvolvimento seja plenamente realizado"; tradução livre e pessoal de "Article 1. Everyone has the right to enjoy peace such that all human rights are promoted and protected and development is fully realized". Disponível em: $<<$ http://undocs.org/en/A/RES/71/189>>, último acesso em 20/04/2017.

38 "Artigo 2. Os Estados devem respeitar, implementar e promover a igualdade e a não-discriminação, a justiça e o Estado de Direito, e garantir o livramento do medo e da miséria como meio de construir a paz dentro das sociedades e entre elas"; tradução livre e pessoal de "Article 2. States should respect, implement and promote equality and nondiscrimination, justice and the rule of law, and guarantee freedom from fear and want as a means to build peace within and between societies". Disponível em: $<<$ http://undocs.org/en/A/RES/71/189>>, último acesso em 20/04/2017.
}

39 «Artigo 5. Nenhuma disposição da presente Declaração será interpretada como contrária aos propósitos e princípios das Nações Unidas. As disposições incluídas na presente Declaração devem ser entendidas de acordo com a Carta das Nações Unidas, a Declaração Universal dos Direitos Humanos e os instrumentos internacionais e regionais relevantes ratificados pelos Estados"; tradução livre e pessoal de "Article 5. Nothing in the present Declaration shall be construed as being contrary to the purposes and principles of the United Nations. The provisions included in the present Declaration are to be understood in accordance with the Charter of the United Nations, the Universal Declaration of Human Rightsand relevant international and regional instruments ratified by States". Disponível em: <<http://undocs.org/en/A/RES/71/189>>, último acesso em 20/04/2017.

40 «Artigo 3. Os Estados, as Nações Unidas e as agências especializadas devem adotar medidas adequadas e sustentáveis para implementar a presente Declaração, em particular a Organização das Nações Unidas para a Educação, a Ciência e a Cultura. As organizações internacionais, regionais, nacionais e locais e a sociedade civil são encorajadas a apoiar e a ajudar na implementação da presente Declaração"; tradução livre e pessoal de "Article 3. States, the United Nations and specialized agencies should take appropriate sustainable measures to implement the 
solidariedade entre todos os seres humanos, deve servir de instrumento básico para a construção e fortalecimento do direito à paz (A/RES/71/189, art. $\left.4^{41}\right)$.

\section{Promoção da paz como requisito vital para o pleno desfrute dos direitos humanos para todos}

Passados dois anos desde a Declaração sobre o Direito à Paz (A/RES/71/189), o $73^{\circ}$ Período de Sessões da Assembleia Geral das Nações Unidas, em 17 de dezembro de 2018, deu por aprovada a A/RES/73/170 42 (Promoção da paz como requisito vital para o pleno desfrute dos direitos humanos para todos), o que o fez em doze disposições apoiadas em densa exposição preambular.

A dita exposição preambular, por agora, pode ser restringida a três justificativas: a um, do necessário cumprimento do objetivo de criar condições de estabilidade e bem-estar, indispensáveis às relações pacíficas e amistosas entre as nações, baseadas no respeito pelos princípios da igualdade de direitos e da autodeterminação dos povos; a dois, a concepção de que a vida sem guerra é o pré-requisito internacional primário para o bem-estar material, desenvolvimento e progresso dos países, bem como para a plena implementação dos direitos e liberdades humanas fundamentais proclamados pelas Nações Unidas; e, a três, a convergente observação de que a cooperação internacional no campo dos direitos humanos contribui para criar um ambiente internacional de paz e estabilidade.

Superadas as restritas justificativas, passa-se ao teor normativo, o que se faz conclamando à disseminação, à compreensão e ao respeito universal da Declaração sobre o Direito a Paz, a todas as associações, especialmente as que compõem o sistema das Nações Unidas (art. $1^{\circ}$ ), sob a renovação da ideia que todos os povos do planeta têm o sagrado direito à paz (art. $2^{\circ}$ ) em que a educação tem importância vital como instrumento para promoção deste fim (art. 10 $0^{\circ}$, bem como que a preservação deste direito e o empenho em sua implementação constitui obrigação

present Declaration, in particular the United Nations Educational, Scientific and Cultural Organization. International, regional, national and local organizations and civil society are encouraged to support and assist in the implementation of the present Declaration". Disponível em: $<<$ http://undocs.org/en/A/RES/71/189 $>>$, último acesso em 20/04/2017.

${ }^{41}$ «Artigo 4. As instituições internacionais e nacionais de educação para a paz devem ser promovidas a fim de fortalecer entre todos os seres humanos o espírito de tolerância, diálogo, cooperação e solidariedade. Para tal, a Universidade para a Paz deve contribuir para a grande tarefa universal de educar para a paz, através do ensino, da investigação, da formação pós-graduada e da difusão do conhecimento"; tradução livre e pessoal de "Article 4. International and national institutions of education for peace shall be promoted in order to strengthen among all human beings the spirit of tolerance, dialogue, cooperation and solidarity. To this end, the University for Peace should contribute to the great universal task of educating for peace by engaging in teaching, research, post-graduate training and dissemination of knowledge". Disponível em: $<<$ http://undocs.org/en/A/RES/71/189>>, último acesso em 20/04/2017.

${ }^{42}$ Disponível em: $<<$ https://www.un.org/en/ga/search/view_doc.asp?symbol=A/RES/73/170>>, último acesso em 30/05/2019. 
fundamental de todos os Estados (art. $\left.3^{\circ}\right)$.

Outrossim, em nível amplo de direitos humanos, concebe a paz como requisito vital para a promoção e a proteção de todos estes direitos em igualdade para todos (art. $4^{\circ}$ ), afirmando que todos os Estados devem promover o estabelecimento, a manutenção e o fortalecimento da paz e da segurança internacionais, e insistir na implementação de um sistema internacional baseado no respeito aos princípios consagrados na Carta e na promoção de todos os direitos humanos e liberdades fundamentais, incluindo o direito ao desenvolvimento e o direito dos povos a autodeterminação (art. $7^{\circ}$ ), de igual modo reafirma o dever de todos os Estados, de acordo com os princípios da Carta, de utilizar meios pacíficos para resolver qualquer litígio que o envolva e cuja continuação seja suscetível de pôr em perigo a manutenção da paz e segurança internacionais, como requisito vital para a promoção e proteção de todos os direitos humanos de todos os seres humanos e de todos os povos (art. $9^{\circ}$ ). Para tanto, convida os Estados e os mecanismos e procedimentos relevantes dos direitos humanos das Nações Unidas a continuar atentos à importância da cooperação, compreensão e diálogo mútuos para assegurar a promoção e proteção de todos os direitos humanos (art. 11 $1^{\circ}$ ).

No âmbito dos compromissos em sentido estrito, destaca que: a) o abismo sempre crescente que divide, ricos e pobres, mundos desenvolvido e em desenvolvimento, marca a maior ameaça a prosperidade global, a paz e segurança, e a estabilidade (art. $\left.5^{\circ}\right)$; b) a preservação e a promoção da paz exigem que as políticas dos Estados sejam direcionadas para a eliminação da ameaça de guerra, particularmente a guerra nuclear, a renúncia ao uso ou ameaça de uso da força nas relações internacionais e a resolução das disputas internacionais pelos meios pacíficos com base na Carta das Nações Unidas (art. $6^{\circ}$ ); e c) todos os Estados devem respeitar e pôr em prática os propósitos e princípios da Carta nas suas relações com outros Estados, independentemente do seu sistema político, econômico ou social e da sua dimensão, localização geográfica ou nível de desenvolvimento econômico $\left(\operatorname{art.} 8^{\circ}\right)$.

\section{Aproximação e harmonia entre ONU e OMS}

Já se disse que a OMS foi pensada desde os debates para criação da ONU, mesmo para fortalecer os organismos sanitaristas anteriores com ênfase na prevenção e intervenção de doenças e enfermidades em nível internacional, o que foi possível por previsão direta na Carta das Nações Unidas ao admitir o vínculo organizacional como entidades especializadas (Carta, Art. $57,2)$, como no caso da OMS por se tratar de entidade criada por acordo intergovernamental com responsabilidade internacional que tem regulamentação em seus instrumentos básicos para conhecer e intervir em questões sanitárias e conexas (Carta, Art. 57, 1).

Em decorrência do Art. 57 da Carta da Nações Unidas, a Constituição da Organização Mundial de Saúde anteviu e permitiu, no Art. 69, a celebração de Acordo entre as instituições dando fruição a regra e a intenção gerais, o que aconteceu após o cumprimento da norma formal de 
quórum privilegiado de dois terços dos votos pela aprovação, na Primeira Assembleia Mundial de Saúde, em 10 de julho de 1948. Em concreto, admite, desde então, o art. $1^{\circ}$ do Termo de Acordo que a ONU reconhece a OMS como agência especializada responsável por tomar as medidas adequadas, nos termos da sua Constituição, para a realização dos objectivos nela estabelecido.

Em tempos de pandemia instaurada pelo COVID-19 vê-se como maior facilidade a proximidade entre as Organizações, especialmente no âmbito da Assembleia Geral das Nações Unidas quando, no atual $74^{\circ}$ Período de Sessões, aprovou três Resoluções em apoio a OMS: uma, de maior envergadura e extensão, prevê o acordo entre os Chefes de Estado e os Chefes de Governo com representação nas Nações Unidas, em nível de Declaração Política, para conceber uma cobertura universal da saúde na busca de um avanço conjunto para construção de um mundo saudável (A/RES/74/2); outra, dedicada a "Solidariedade global para combater a doença coronavírus" (A/RES/74/270); e, uma terceira, cingida à "Cooperação internacional para garantir o acesso global a remédios, vacinas e equipamentos médicos para enfrentamento do COVID-19" (A/RES/74/274).

Constituição da OMS: princípios institucionais básicos e a aderência a cultura de paz

A Constituição da OMS (The Constitution of World Health Organization) é o documento formal institutivo da entidade aprovado na Conferência Internacional de Saúde ocorrido em 1946, com a subsequente assinatura, em 22 de julho, pelos representantes dos sessenta e um países, e vigência a partir de 7 de abril de 1948. Desde então, foram propostas quatro Emendas incorporadas ao texto base por aprovação em Assembleia: a) WHA 26.37 (26 $6^{\text {a }}$ Sessão, 03/02/1977); b) WHA 29.38 (29a Sessão, 20/01/1984); c) WHA 39.6 (39 Sessão, 11/07/1994; e, d) WHA 51.23 ( $51^{\text {a }}$ Sessão, 15/09/2005).

Em nível de princípios, determina o Preâmbulo, para além da adequação à Carta das Nações Unidas, que são básicos para a felicidade, relações harmoniosas e segurança dos povos (rectius, de todas as pessoas), nos seguintes termos: a) a saúde é um estado de completo bem-estar físico, mental e social, não apenas a ausência de doenças ou enfermidades; b) O gozo do mais alto padrão de saúde atingível é um dos direitos fundamentais de todo ser humano sem distinção de raça, religião, crença política, condição econômica ou social; c) a saúde de todos os povos é fundamental para consecução da paz e segurança, sendo dependente da mais ampla cooperação de indivíduos e Estados; d) a realização de qualquer Estado na promoção e proteção da saúde é de valor para todos; e) o desenvolvimento desigual em diferentes países na promoção da saúde e no controle das doenças, especialmente as doenças transmissíveis, é um perigo comum; f) o desenvolvimento saudável da criança é de importância básica, e a capacidade de viver harmoniosamente em um ambiente total em mudança é essencial para tal desenvolvimento; g) a extensão a todos os povos dos benefícios dos conhecimentos médicos, psicológicos e afins é 
essencial para a realização plena da saúde; h) a opinião informada e a cooperação ativa por parte do público são da maior importância para a melhoria da saúde da população; i) os governos têm responsabilidade pela saúde dos seus povos que só pode ser cumprida através de medidas sanitárias e sociais adequadas.

Em atenção ao art. 69 da Constituição da OMS e do art. 57 da Carta das Nações Unidas foi celebrado o Acordo entre as entidades. Assim, para além do reconhecimento do princípio básico que vincula a saúde de todos - indivíduos e povos - como fundamental para a consecução da paz (Preâmbulo da Constituição da OMS), determinou-se o dever da OMS em fornecer informações e prestar assistência para a manutenção ou restauração da paz e segurança internacionais, cooperando, portanto, com o Conselho de Segurança das Nações Unidas para consecução deste fim em comum (Acordo, art. $7^{\circ}$ ).

Em convergência, tem-se que a persecução da paz internacional duradoura (quiçá perpétua) é um objetivo comum alçado a nível de princípio básico e fundamental para ambas as instituições, cujo método de difusão prática é a formação da consciência de que a paz deve ser construída na mente dos indivíduos, e, é aí, que deve ser semeado o sentimento que a saúde é fundamental para consecução da paz.

\section{A/RES $/ 74 / 2^{43}$}

Qual pese o eixo temático da presente análise se cingir aos aspectos pandêmicos ocasionados pelo COVID-19 no âmbito da cultura de paz - portanto de interesse conjunto da $\mathrm{OMS}^{44}$ e da ONU -; não se pode deixar de mencionar a importância da A/RES/74/2 que introduziu a "Declaração política da reunião de alto nível sobre a cobertura universal da saúde" dedicada ao avanço conjunto para se construir um mundo mais saudável.

Em poucas palavras, do extenso e complexo documento contendo 84 artigos, por agora, duas disposições mais interessam: a um, a reafirmação em nível política que a saúde é uma condição prévia para o resultado, além de indicar o próprio resultado, bem como indicador das dimensões social, econômica e ambiental do desenvolvimento sustentável, portanto de interesse para implementação da Agenda para o Desenvolvimento Sustentável de 2030, de sorte que se confirma fortemente o compromisso de alcançar uma cobertura universal da saúde até 2030, com vista a aumentar o esforço global para construir um mundo mais saudável para todos (A/RES/74/2, Preâmbulo); e, a dois, que as metas de desenvolvimento sustentável não se restringem apenas a saúde e ao bem-estar, mas refletem erradicação da pobreza em todas as suas formas e dimensões, na consecução da educação de qualidade, no alcance da igualdade de gênero

\footnotetext{
${ }_{43}$ Disponível em: $<<$ https://undocs.org/en/A/RES/74/2>>, último acesso em 30/07/2020.

${ }^{44}$ Apenas para identificação, a OMS é mencionada em sete artigos da A/RES/74/2: art. 32, art. 43, art. 50, art. 62, art. 80 , art. 81 e art. 82.
} 
e o empoderamento das mulheres, na prestação do trabalho decente e na consecução do crescimento econômico, e na redução das desigualdades, assegurando sociedades justas, pacíficas e inclusivas (A/RES/74/2, art. 5).

\section{A/RES $/ 74 / 270^{45}$}

Avançada a análise, percebe-se a proximidade e afinidade de propósitos entre OMS e ONU, sendo a persecução da paz internacional um princípio básico e fundamental que as une, elevandoa ao nível de objetivo, neste caso, direcionado à proteção dos indivíduos, independentemente de suas peculiaridades (gênero, etnia, cor, nacionalidade, religião, cultura, etc.), mediante a prevenção e contenção de doenças e enfermidades. No cumprimento dessa missão se revela a solidariedade que, a mais das vezes, converge à cooperação que estimula o diálogo, a tolerância e o respeito, fundamentos para consecução da paz, e princípios estruturantes da cultura de paz.

Reproduzindo na prática esta construção lógica, pouco mais de três semanas após a OMS declarar a situação de pandemia em razão do "coronavirus disease 2019 (COVID-19)", a ONU, em 02 de abril de 2020, aprovou a A/RES/74/270 estimulando o engajamento de todos, povos e países, indivíduos e governos, sociedade civil e organismos internacionais, na luta contra a irradiação da pandemia; em síntese propôs "a solidariedade global para combater a doença coronavírus".

Como fundamento da Resolução, reconheceu-se: a) os efeitos sem precedente da pandemia, com perturbação das sociedades, das economias, das viagens e do comércio, além do impacto devastador a subsistência dos indivíduos; b) os prejuízos dos avanços conquistados no âmbito da Agenda 2030 para o desenvolvimento sustentável (A/RES/70/1) com a triste constatação que os mais pobres e vulneráveis tendem a ser mais duramente atingidos; c) a importância do papel crucial da OMS no combate do COVID-19, assim como do sistema das Nações Unidas em somar esforços para o resultado favorável desta empreitada mediante a catalisação e coordenação da resposta ao controle e disseminação da doença; d) os esforços gerais para sucesso das medidas de proteção da saúde, da segurança e do bem-estar de todos, implementados pelos governos, os profissionais da área de saúde, e todos os que estão na linha de frente do combate; e) os requisitos para a resposta a pandemia, a unidade, a solidariedade e a renovação da cooperação multilateral; e, por fim, f) o trabalho deve ser feito em conjunto, a nível nacional, regional e global, para garantir que ninguém seja deixado apra trás (um interessante lema: "to ensure that no one is left behind"!)

Outrossim, a Resolução acolheu o apelo do Secretário-Geral das Nações Unidas para destaque: a) ao enfretamento da emergência sanitária; b) concentração no impacto social e nas necessárias medidas econômicas a serem adotadas; e, c) a ênfase na necessidade de uma

\footnotetext{
${ }^{45}$ Disponível em: $<<$ https://undocs.org/en/A/RES/74/270>>, último acesso em 30/07/2020.
} 
recuperação sustentável e inclusiva, ou seja, no âmbito da Agenda para o desenvolvimento sustentável e aderência a cultura de paz.

O conteúdo propositivo da A/RES/74/270 pode ser lido de diversas maneiras, inclusive a que distribui o tema em dois pontos: o compromisso (cingido ao art. 1 complementado pelo art. 5, art. 7. art. 8 e art. 9); e a limitação (previsto no art. 2 com reflexos no art. 3, art. 4 e art. 6).

O compromisso é percebido no empenho na cooperação internacional e no multilateralismo, bem como no forte apoio ao papel central do sistema das Nações Unidas na resposta global à pandemia por COVID-19 (A/RES/74/270, art. 1). Em rápida leitura, observa-se que o núcleo desta definição recai em três elementos: cooperação internacional, multilateralismo e resposta global.

No âmbito da cooperação internacional (elemento de maior ênfase) é possível culminar outras proposições, tais como: a) o interesse em conter, atenuar e eliminar a pandemia, com estímulo a troca de informação, partilha de conhecimento científico e tratamentos eficazes, além de observância às recomendações da OMS (A/RES/74/270, art. 5); b) manter a busca pelo desenvolvimento sustentável pelo que o sistema das Nações Unidas deve funcionar como um só no apoio aos governos (A/RES/74/270, art. 7); c) a cooperação e a solidariedade enquanto princípios a serem adotados pelas lideranças globais aliviarão e reverterão com sucesso os efeitos da pandemia (A/RES/74/270, art. 8); e, d) o convite para que o sistema das Nações Unidas, sob a liderança do Secretário-Geral, trabalhe com todos os atores relevantes, a fim de mobilizar uma resposta global coordenada à pandemia e ao seu impacto social, econômico e financeiro, em todas as sociedades (A/RES/74/270, art. 9).

A limitação, nos termos do art. 2 da A/RES/74/270, recai no pleno respeito aos direitos humanos, não sendo admitido em resposta a pandemia, em nenhuma hipótese e forma, a discriminação, o racismo e a xenofobia. Em complemento, acrescem-se três proposições: a) as profundas condolências às famílias e sociedades dos mortos pela doença, além daqueles que tiveram suas vidas e subsistência afetadas pela crise (A/RES/74/270, art. 3); b) a gratidão e apoio aos que estão na linha de frente de combate a pandemia (A/RES/74/270, art. 4); c) o reconhecimento da assistência e apoio prestadas por inúmeros governos em espírito de solidariedade apoios recíprocos (A/RES/74/270, art. 6, segunda parte); e, d) o compromisso de ajudar pessoas e sociedades em condições especiais, como o são os mais fracos e vulneráveis ${ }^{46}$ (A/RES/74/270, art. 6, primeira parte).

\section{A/RES $/ 74 / 274^{47}$}

Poucos dias após a aprovação daA/RES/74/270, em 20 de abril de 2020, a Assembleia Geral

\footnotetext{
${ }^{46}$ Há, aqui, uma dúplice possibilidade de leitura sobre esta proposição: a um, pelo próprio valor semântico ínsito na palavra "compromisso"; e, outro, pela finalidade do dispositivo em reportar um valor humano inerente a construção dos direitos humanos. Preferiu-se o segundo.

${ }^{47}$ Disponível em: <<https://undocs.org/en/A/RES/74/274>>, último acesso em 30/07/2020.
} 
das Nações Unidas aprovou a A/RES/74/274. Valendo-se das premissas das duas correlatas Resoluções anteriores, convergiu o compromisso e a limitação assentados para o combate solidário global ao Coronavírus (A/RES/74/270) em convergência à declaração política sobre a cobertura mundial da saúde (A/RES/74/2), no sentido de estimular a cooperação internacional para garantir o acesso global a remédios, vacinas e equipamentos médicos para combate ao COVID-19 (A/RES/74/274).

Manteve-se a ideia do compromisso no empenho na cooperação internacional e no multilateralismo, bem como no forte apoio ao papel central do sistema das Nações Unidas na resposta global à pandemia por COVID-19 (A/RES/74/270, art. 1); renovando-se, portanto, o núcleo da definição em três elementos (cooperação internacional, multilateralismo e resposta global), embora sobre a perspectiva da resposta global dever ser baseada na unidade, na solidariedade e na cooperação multilateral (A/RES/74/274, Preâmbulo), bem como estender o protagonismo das ações para a OMS e outras entidades congêneres (incluindo as de natureza financeira) do sistema da ONU (A/RES/74/274, art. 1, art. 2 e art. 5).

O Preâmbulo da A/RES/74/274 permite observar, em leitura conjunta com a A/RES/74/270, três novos pontos: a garantia, o objetivo e a finalidade da "cooperação multilateral" (representativa da reunião, por afinidade funcional, da cooperação internacional e do efetivo multilateralismo).

A garantia indica que todos os seres humanos, sem distinção, têm o direito à saúde física e mental; o que leva ao objetivo de lhes reconhecer o acesso equitativo aos produtos de saúde como prioridade global, de sorte que a disponibilidade, acessibilidade, aceitabilidade e acessibilidade dos produtos de saúde de qualidade garantida são fundamentais para enfrentar a pandemia; em convergência, a cooperação multilateral tem especial importância para a realização do objetivo quando empregada no sentido de garantir que os Estados implementem práticas nacionais de garantia de medidas de acesso e fruição de suprimentos médicos vitais, remédios e vacinas.

Na prática, a cooperação multilateral, neste aspecto, se presta a estimular e orientar, eficaz e rapidamente, o desenvolvimento, a fabricação e a distribuição dos suprimentos médicos e afins, vacinas, testes laboratoriais, remédios, etc. (A/RES/74/274, art. 2 e art. 3); ao mesmo tempo em que se deve prevenir, com fundamento em seus ordenamentos jurídicos, especulações e acumulação indevida de estoques que possam impedir o acesso a medicamentos essenciais, vacinas, equipamento de proteção pessoal e médico seguros, eficazes e acessíveis, conforme for necessário para enfrentar eficazmente a COVID-19 (A/RES/74/274, art. 4).

\section{Conclusão}

Ao relembrar que a intenção da presente análise foi a de refletir sobre a relação da cultura de paz, em discurso positivo e propositivo, diante do atual desafio pandêmico, com ênfase nas 
Resoluções das Nações Unidas que têm relação direta com a OMS, desde as vinculadas à instauração do sistema de paz da ONU até aquelas tomadas no atual Período de Sessões que se referem diretamente a pandemia e se prestam a convergir os fundamentos do sistema de paz, especialmente a cultura de paz, à cooperação internacional em multilateralismo para uma resposta global eficaz no combate ao COVID-19; é que se substitui a conclusão por considerações finais.

Assim, em palavras finais, propõe-se, mais do que uma conclusão (mesmo porque seria impossível diante da proposta de estímulo a reflexão e, não, de proposta de solução ao problema em si), algumas considerações para que o atento leitor possa manter-se em reflexão, propositiva e positiva, sobre o tema. Veja-se:

1. Há que se fortalecer a consciência que a saúde de todos, em iguais condições de acesso, é fundamental para o fortalecimento do sentimento de paz. Afinal, é na mente humana que se deve semear os valores de saúde e paz;

2. A cultura de paz e a busca do direito a saúde física e mental são compromissos de todos, inclusive dos sanitaristas;

3. A difusão dos valores de saúde, na óptica da cultura de paz, pressupõe a prática do princípio da cooperação que conduza à tolerância e ao diálogo, num ambiente de respeito entre os iguais ainda que no acesso ao tratamento médico, ou até mesmo na prevenção à doenças e/ou enfermidades;

4. Tal perspectiva contribui para, normativamente, sistematizar as Resoluções com a determinação dos cinco pontos (compromisso, limitação, garantia, objetivo e finalidade da cooperação multilateral, conforme analisados, diretamente na A/RES/74/270 e na A/RES/74/274, e indiretamente na $\mathrm{A} / \mathrm{RES} / 74 / 2$ ) que, além de permitirem a leitura lógico-jurídica, ainda fortalecem a consciência pela paz e saúde, ou se preferir, a leitura da saúde pelos valores ínsitos na cultura de paz.

5. Enfim, a paz e a saúde, como direitos ou como culturas, devem ser constantemente semeadas na mente humana, mas devem ser estimuladas e praticadas, por todos, Estados e sociedade civil, povos e indivíduos.

\section{Referências}

League of Nations. Health Organisation. Geneva: Information Section, 1931.

PIRES, Alex Sander Xavier. Sistema de paz no âmbito das Nações Unidas e estados constitucionais. In, Rosário, Pedro Trovão; et al. [org.], Direito Constitucional Luso e Brasileiro no âmbito da pacificação social. Porto: Juruá, 2020; pp. 37-61.

Da inversão do paradigma teórico-prático até a atual concepção da paz como requisito vital para o pleno desfrute dos direitos humanos em igualdade. In, Galileu, Revista de Direito e Economia, v. XX(1), jan.-jun., 2019, pp. 78-98. 
Fluxos migratórios forçados e cultura de paz: um contributo hiptético baseado na educação como pilar da democracia e na solução alternativa à crise do estado assistencialista. In, Galileu, Revista de Direito e Economia, v. XIX (1), jan.-jun., 2018, pp. 66-85.

World Health Organization. Agreement between the United Nations and the World Health Organization. In, Basic Documents, 19 ed. Genebra: World Health Organization, 2020; pp. 44-53.

World Health Organization. Constitution of World Health Organization. In, Basic Documents, 19 ed. Genebra: World Health Organization, 2020; pp. 1-20.

\section{Referências normativas:}

A/RES/3/190. Disponível em: $<<$ https://www.un.org/en/ga/search/view_doc.asp?symbol=A/RES/190(III) $>>$, último acesso em 30/05/2019.

A/RES/3/217. Disponível em:

$<<$ https://www.un.org/en/ga/search/view_doc.asp?symbol=A/RES/217(III) $>>$, último acesso em 30/05/2019.

A/RES/4/290. Disponível em:

$<<$ http://www.un.org/en/ga/search/view_doc.asp?symbol=A/RES/290(IV) $>>$, último acesso em 11/03/2019.

A/RES/5/377. Disponível em:

$<<$ http://www.un.org/en/ga/search/view_doc.asp?symbol=A/RES/377(V) $>>$, último acesso em $12 / 03 / 2019$.

A/RES/5/380. Disponível em:

$<<$ http://www.un.org/en/ga/search/view_doc.asp?symbol=A/RES/380(V) >>, último acesso em $12 / 03 / 2019$.

A/RES/5/381. Disponível em:

$<<$ http://www.un.org/en/ga/search/view_doc.asp?symbol=A/RES/381(V) >>, último acesso em $12 / 03 / 2019$.

A/RES/5/494. Disponível em:

$<<$ http://www.un.org/en/ga/search/view_doc.asp?symbol=A/RES/494(V) $>>$, último acesso em $12 / 03 / 2019$.

A/RES/53/243. Disponível em:

$<<$ https://www.un.org/en/ga/search/view_doc.asp?symbol=A/RES/53/243 $>>$, último acesso em 30/05/2019.

A/RES/70/1. Disponível em: $<<$ https://undocs.org/en/A/RES/70/1 >>, último acesso em $14 / 07 / 2020$.

A/RES/71/189. Disponível em:

$<<$ https://www.un.org/en/ga/search/view_doc.asp?symbol=A/RES/71/189>>, último acesso em 30/05/2019.

A/RES/73/170. Disponível em:

$<<$ https://www.un.org/en/ga/search/view_doc.asp?symbol=A/RES/73/170 >>, último acesso em 30/05/2019.

A/RES/73/342. Disponível em: <<https://undocs.org/en/A/RES/73/342>>, último acesso 
em 14/07/2020.

A/RES/74/2. Disponível em: $<<$ https://undocs.org/en/A/RES/74/2>>, último acesso em 30/07/2020.

A/RES/74/270. Disponível em: $<<$ https://undocs.org/en/A/RES/74/270>>, último acesso em 30/07/2020.

A/RES/74/274. Disponível em: $<<$ https://undocs.org/en/A/RES/74/270>>, último acesso em 30/07/2020.

Acordo de St. James. Disponível em: $<<$ http://avalon.law.yale.edu/imt/imtjames.asp $>>$, último acesso em 30/05/2019.

Carta das Nações Unidas. Disponível em:

$<<$ http://dag.un.org/bitstream/handle/11176/387353/PORTUGUESE1976.pdf?sequence=1\&isAllowed=y $>>$, último acesso em 30/05/2019.

Declaração da Filadélfia. Disponível em:

$<<$ https://www.ilo.org/dyn/normlex/en/f?p=1000:62:0::NO:62:P62_LIST_ENTRIE_ID:24539 07:NO\#declaration>>, último acesso em 09 de julho de 2020.

Tratado de Versalhes. Disponível em: $<<$ https://www.loc.gov/law/help/ustreaties/bevans/m-ust000002-0043.pdf $>>$, último acesso em 09 de julho de 2020.

\section{Referências digitais:}

$<<$ https://www.who.int/news-room/detail/27-04-2020-who-timeline---covid-19>>, último acesso em 30/07/2020. 